\title{
Bimbingan Teknis Kinerja Pengawas Tempat Pemungutan Suara pada Pilkada 2020 di Era Pandemi Covid 19
}

\author{
Technical guidance the performance of the vote point supervisors in the 2020 elections \\ in the covid-19 pandemic era
}

\author{
Ricky Santoso Muharam \\ MKWU PPKn, Sekolah Tinggi Pariwisata Ambarrukmo Yogyakarta, Bantul, Indonesia \\ ricky@stipram.ac.id
}

Riwayat Artikel: Dikirim 17 Juni 2021; Diterima 23 September 2021; Diterbitkan 30 November 2021

\begin{abstract}
Abstrak
Pemahaman tentang tugas sebagai pengawas tempat pemungutan suara tentunya perlu diberikan secara menyeluruh tentang berbagai materi dari mulai regulasi tentang pemilihan kepala daerah, regulasi tentang pengawasan pemilihan kepala daerah di masa pandemi Covid-19, kode etik dan penggunaan sistem pengawasan pemilu (SIWASLU) perlu dipahami dengan jelas. Kegiatan ini dilakukan dua tahap yakni bimbingan teknis tahap 1 dan bimbingan teknis tahap 2 dimulai dari tahap persiapan, pengarahan materi, praktek, post tes dan pengisian kuesioner. Hasil kegiatan ini menghasilkan pemahaman bagi anggota pengawas tempat pemungutan suara (PTPS) dalam menjalankan tanggung jawabnya dari pemahaman regulasi, pengawasan protokol kesehatan sebagai pengawas, kode etik serta komitmen untuk turut andil menjadi PTPS. komitmen PTPS untuk dapat berkontribusi kembali menjadi anggota pengawas pemilu TPS untuk pemilu 2024 responden menjawab 28 orang $(47,5 \%)$ bersedia kembali untuk menjadi PTPS pada pemilu atau pilkada yang akan datang, 28 orang $(47,5 \%)$ menjawab masih ragu atau mungkin bersedia kembali untuk menjadi PTPS dan 3 orang atau sekitar (5,1\%) tidak ingin bergabung menjadi anggota PTPS untuk Pilkada atau Pilpres tahun 2024.
\end{abstract}

Kata kunci: Pilkada 2020, Pengawas Pemilu, Covid-19

\begin{abstract}
Understanding of duty as a supervisor of polling places certainly needs to be given a thorough of various materials ranging from regulations on the selection of regional heads, regulations on the supervision of regional head elections during the Covid-19 pandemic, the code of ethics and the use of the election surveillance system (SIW ASLU) need to be clearly understood. This activity is carried out in two stages, namely technical guidance phase 1 and technical guidance phase 2 starting from the preparatory stage, material briefing, practice, posttest and questionnaire filling. The results of this activity resulted in understanding for members of the polling station supervisor (PTPS) in carrying out their responsibilities from regulatory understanding, supervision of bealth protocols as supervisors, code of etbics and commitment to contribute to becoming PTPS. PTPS commitment to be able to contribute back to become a member of the TPS election supervisor for the 2024 elections correspondents answered 28 people (47.5\%) willing to return to become PTPS in the upcoming elections or local elections, 28 people (47.5\%) answer still in doubt or maybe willing to return to become PTPS and 3 people or about (5.1\%) do not want to join the PTPS for the 2024 regional elections or presidential elections.
\end{abstract}

Keywords: Election 2020, Election Supervisor, Covid-19.

\section{PENDAHULUAN}

Pesta demokrasi di Indonesia untuk memilih calon pemimpin putera-puteri terbaik khususnya pada pemilihan kepala daerah tahun 2020 menuai pro dan kontra karena Pilkada 2020 diselenggarakan pada masa pandemic Covid 19. Banyak yang mengkhawatirkan

penyelenggaraan pemilihan kepala daerah baik Gubernur dan Wakil Gubernur, Bupati dan Wakil Bupati serta Walikota dan Wakil Walikota.

Pilkada serentak sebelumnya dilaksanakan pada tahun 2015 (Pilkada serentak Pertama), tahun 2017 (Pilkada 
serentak kedua) dan tahun 2018 (Pilkada serentak ketiga) dan untuk Pilkada 2020 merupakan Pilkada serentak keempat (Supriyadi, 2020).

Tercatat pada tahun 2020 pilkada yang akan diselenggarakan untuk memilih calon pemimpin daerah berjumlah 270 daerah dengan rincian 9 provinsi, 224 kabupaten dan 37 kota ditambah satu daerah Pilkada Kota Makassar karena diulang pelaksanaanya (Aida, 2020). Pilkada serentak yang sebelumnya mengalami ketidakpastian dan penundaan karena wujud antisipasi serta kewaspadaan tentang wabah Covid-19 di Indonesia (Rizki \& Hilman, 2020).

Pada akhirnya Pilkada 2020 mendapatkan kepastian dengan dikeluarkannya regulasi Peraturan Pemerintah Pengganti Undang-Undang (Perppu) No 2 Tahun 2020 (Chusna, 2020). Seperti tercantum didalam Perppu No 2 tahun 2020 Pasal 120 ayat 1 dan 2 yang berbunyi:

(1) Dalam hal pada sebagian wilayah Pemilihan, seluruh wilayah Pemilihan, sebagian besar daerah, atau seluruh daerah terjadi kerusuhan, gangguan keamanan, bencana alam, bencana non alam, atau gangguan lainnya yang mengakibatkan sebagian tahapan penyelenggaraan Pemilihan atau Pemilihan serentak tidak dapat dilaksanakan, dilakukan Pemilihan lanjutan atau Pemilihan serentak lanjutan.

(2) Pelaksanaan Pemilihan lanjutan atau Pemilihan serentak lanjutan sebagaimana dimaksud pada ayat (1) dimulai dari tahapan penyelenggaraan Pemilihan atau Pemilihan serentak yang terhenti (Pengganti UndangUndang, 2020).

Berdasarkan regulasi diatas tentunya proses pelaksanaan Pilkada 2020 yang sempat terhenti karena pandemi Covid-19 dapat dilaksanakan kembali dengan dilengkapi regulasi yang terkait dengan Pilkada 2020 serta aturan tentang protokol kesehatan.

Dalam proses pelaksanaan atau penyelenggaraan Pilkada 2020 tentunya perlu ada kesiapan yang matang dalam melaksanakan pesta demokrasi khususnya di era pandemic Covid 19. Kesiapan dari penyelenggara KPU, Bawaslu serta DKPP perlu melakukan pertimbangan serta pemahaman teknis dalam proses pelaksanaan Pilkada 2020. Khususnya bagi penyelenggara di tingkat bawah seperti KPPS dibawah KPU serta PTPS dibawah Bawaslu.

Kesuksesan dalam penyelenggaraan Pilkada 2020 di era pandemi tentunya yang menjadi garda terdepan dalam memperjuangkan serta keberhasilan dalam pesta demokrasi yakni di jajaran bawah, seperti Pengawas Tempat Pemungutan Suara (PTPS) secara penugasan dibawah Pengawas Desa/Kelurahan serta di bawah Pengawas Pemilihan Kecamatan. Pengawas Tempat Pemungutan Suara (PTPS) tentunya disesuaikan dengan jumlah kebutuhan di setiap TPS untuk diawasi dalam proses penyelenggaraan Pilkada 2020. Tentunya tidak mudah untuk menjadi PTPS terutama dimasa Covid 19 dengan penuh pertimbangan serta tanggung jawab yang bertambah. Selain untuk proses rekrutmen untuk PTPS berbeda dengan KPPS serta tingkat minat masyarakat untuk ikut menjadi bagian pengawas tempat pemungutan suara tidaklah mudah, apalagi kekhawatiran karena adanya pandemic Covid 19 membuat proses rekrutmen menjadi terkendala. Salah satunya yakni di Kecamatan Kretek Kabupaten Bantul Daerah Istimewa Yogyakarta membentuk Kelompok Kerja untuk merekrut calon pengawas tempat pemungutan suara (PTPS) untuk memenuhi kuota pendaftar sesuai dengan jumlah TPS di Kecamatan Kretek yang berjumlah 51 TPS.

$$
\text { Kelompok kerja (Pokja) }
$$

Pembentukan Pengawas TPS melakukan sosialisasi melalui forum-forum warga, spanduk dan pamflet yang ditempelkan di tempat-tempat strategis di tiap-tiap Dusun di Wilayah Kecamatan Kretek. Media Sosial juga menjadi sarana untuk mensosialisasikan Pembentukan Pengawas TPS antara lain melalui WhatsApp Grup. Pengumuman Pendaftaran Pengawas TPS dimulai 30 September 2020 sampai dengan 2 Oktober 
2020. Melalui Pengumuman Pendaftaran Calon Pengawas TPS Nomor; P.036/PANWASLUCAM-

$\mathrm{KRT} / \mathrm{K} / \mathrm{KP} / 09 / 2020$ tertanggal 30 September 2020, yang kemudian disampaikan kepada Lurah Desa dan Dukuh seKecamatan Kretek untuk dapat disosialisasikan kepada masyarakat. Selanjutnya PTPS yang terpilih dilakukan pelantikan secara serentak se-Indonesia pada tanggal 16 November 2020. Khususnya untuk PTPS di wilayah Kecamatan Kretek berdasarkan Surat Keputusan Ketua Panwaslu Kecamatan Kretek Nomor P.003/KPTS/PANWASLUCAM-

KRT/K/KP/11/2020 tanggal 16 November 2020 tentang Penetapan Pengawas TPS seKecamatan Kretek pada Pemilihan Bupati dan Wakil Bupati Kabupaten Bantul tahun 2020 secara resmi dilantik dengan menandatangani Berita Acara, Pembacaan Sumpah janji dan Pakta Integritas.

Kegiatan selanjutnya yaitu dengan diadakannya bimbingan teknis tentu saja sangat diperlukan untuk pemahaman kinerja tugas pengawasan ditingkat TPS dengan demikian Panwaslu Kecamatan mengadakan bimbingan teknis (Bimtek). Bimtek ini sangat diperlukan untuk memberikan pemahaman bagi PTPS untuk melakukan kinerja selama satu bulan penuh sebelum bertugas untuk mengawasi proses penyelenggaraan Pilkada 2020 agar sesuai dengan regulasi yang berlaku.

Karena tingkat Pendidikan serta latar belakang PTPS yang berbeda-beda maka diselenggarakan bimtek tahap 1 dan bimtek tahap 2 untuk memberikan pemahaman terkait tugas pengawasan, regulasi, komitmen, kode etik, integritas serta pengawasan di masa Pandemi Covid-19.

\section{METODE}

Metode yang digunakan pada
kegiatan Pengabdian ini dengan
menggunakan pendekatan langsung,
ceramah, praktik dan post test dan pengisian
kuesioner untuk melihat hasil dari pelatihan
bimtek tahap satu dan bimtek tahap dua dengan beberapa tahapan pelaksanaan kegiatan yaitu:

\section{Persiapan}

Pada bimbingan teknis tahap 1 sebelumnya para Pengawas Tempat Pemungutan Suara (PTPS) terlebih dahulu dilantik secara serentak pada tanggal 16 November 2020 di Balai Desa Tirtomulyo, Kecamatan Kretek dilanjutkan dengan pemaparan materi tentang pengawasan pada Pilkada 2020 serta regulasi tentang Pengawasan di Era Pandemi Covid-19.

\section{Pengarahan Materi}

1). Bimbingan Teknis I:

a. Tugas, wewenang dan kewajiban Pengawas TPS menurut Undang Undang Nomor 7 tahun 2020 tentang Pemilihan Umum

b. Kegiatan pengawasan yang akan dilakukan Pengawas TPS

c. Tugas Pengawas TPS pada Masa Tenang dan Hari Pemungutan \& Penghitungan Suara.

d. Pengawasan di era pandemi Covid-19

e. Rencana Rapid Diagnostic Test (RDT) untuk Pengawas TPS.

Gambar 1: Bimbingan Teknis I

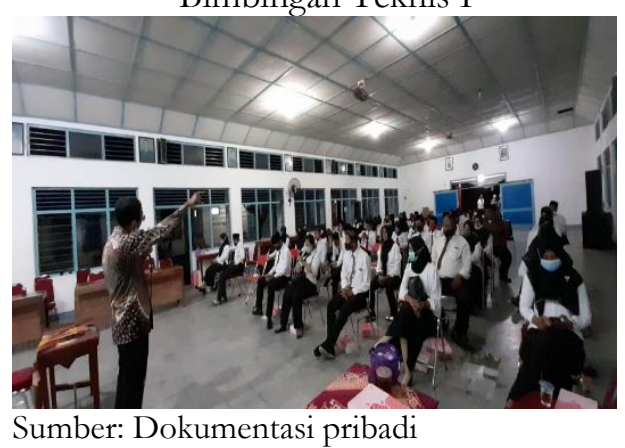

2). Bimbingan Teknis II dilaksanakan pada tanggal 5 Desember 2020 bertempat di Balai Desa Tirtomulyo, Kretek. Dalam Bimbingan Teknis II ini diharapkan Pengawas TPS dapat mengerti dan memahami tupoksinya serta dapat menjalankan tugas pengawasan dengan baik di TPS masing-masing. Materi yang disampaikan antara lain: 
a. Pembuatan Form A Pengawasan

b. Pengisian Aplikasi SIWASLU

c. Pengawasan pada masa tenang dan hari pemungutan penghitungan suara

Gambar 2:

Bimbingan Teknis II

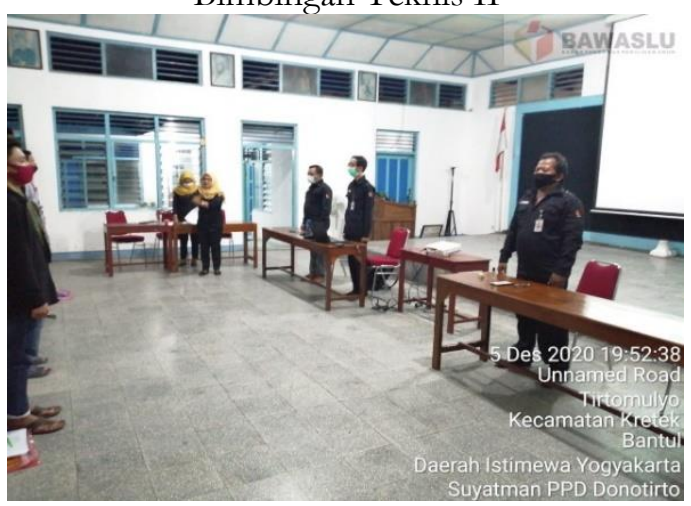

Sumber: Dokumentasi pribadi

\section{Praktek Penggunaan Aplikasi}

Untuk dapat memahami tentang tanggung jawab tentang tugas pengawasan tentunya Pengawas TPS diajarkan pelatihan untuk menggunakan Aplikasi Siwaslu (Sistem Pengawas Pemilu) yang dapat dioperasikan di handphone berbasis android. Pelatihan ini sebagai uji coba serentak yang dilakukan oleh Pengawas PTPS se Indonesia untuk melihat pemahaman serta berjalannya aplikasi tersebut sebelum digunakan pada hari pemungutan suara.

\section{Post Test}

Post Test dilakukan untuk mengetahui pemahaman Pengawas PTPS terkait beberapa materi yang disampaikan oleh narasumber sebagai evaluasi untuk melihat kemampuan PTPS dalam memahami semua materi yang disampaikan untuk perbaikan bimtek yang akan dating.

\section{Pengisian Kuesioner}

Pengisian Kuesioner dilakukan untuk melihat hasil serta sebagai pertimbangan untuk membuat laporan serta membuat publikasi ilmiah di jurnal pengabdian masyarakat.

\section{HASIL DAN PEMBAHASAN}

Berdasarkan data laporan dari Panwaslu Kecamatan Kretek (Muharam et al., 2021) jumlah Pengawas Tempat Pemungutan Suara (PTPS) di Kecamatan Kretek berjumlah 72 orang yang terdiri dari Desa Donotirto 21 orang, Desa Tirtomulyo berjumlah 17 orang, Desa Tirtosari berjumlah 11 orang, Desa Parangtritis berjumlah 21 orang dan Desa Tirtohargo berjumlah 6 orang.

Gambar 3:

Peserta Bimtek PTPS wilayah Kecamtan Kretek

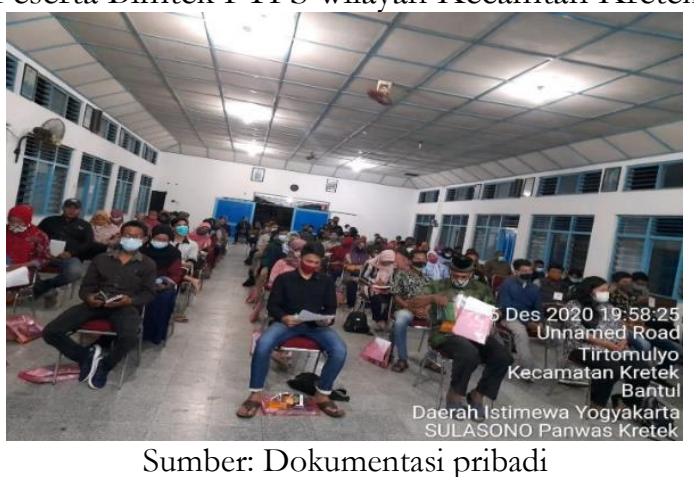

Jumlah PTPS yang terpilih disesuaikan dengan kondisi jumlah TPS yang ditentukan oleh KPU di setiap wilayah daerah pemilihan dengan mempertimbangkan jumlah penduduk dan jumlah pemilih. PTPS yang terpilih dan sudah dilantik diberikan pemahaman materi tentang Pilkada 2020 di era pandemic Covid-19 yang melanda di sejumlah daerah termasuk di Indonesia khususnya di Kabupaten Bantul. Pemahaman Bimtek diperlukan agar PTPS yang terpilih mampu memahami semua materi serta tahu tentang tupoksi dalam tugas pengawasan yang.

Berdasarkan jumlah anggota PTPS di wilayah Kecamatan Kretek yang tersebar di lima desa yang bersedia untuk mengisi kuesioner yakni sekitar 59 orang dari total 72 orang. Hasil pengiriman angket terdapat 59 orang yang terdiri dari 26 berjenis kelamin laki-laki $(44,1 \%)$ dan berjenis kelamin perempuan berjumlah 33 orang $(55,9 \%)$. Memberikan respon dari Desa Donotirto 20 orang atau sekitar 33,9\%, Desa Tirtomulyo 
berjumlah 14 orang atau sekitar 23,7\%, Desa Tirtosari berjumlah 11 orang atau sekitar 18,6\%, Desa Parangtritis berjumlah 8 orang atau sekitar 13,6\% dan Desa Tirtohargo berjumlah 6 orang atau sekitar 10,2\%. Untuk dapat lebih jelasnya dapat dilihat pada Gambar.4 dibawah ini:

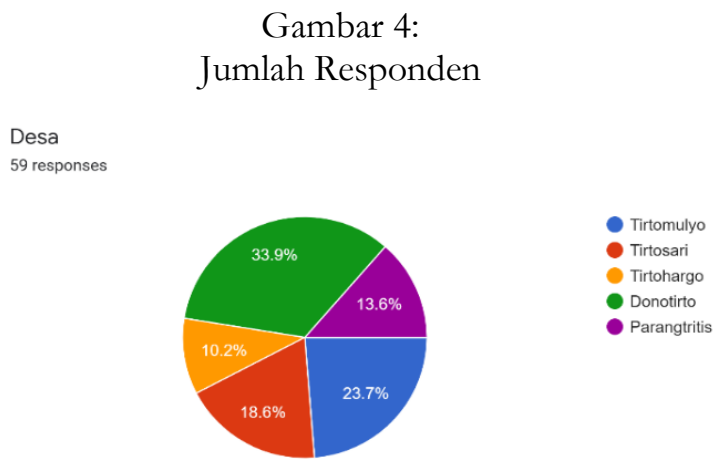

Sumber: Dokumentasi pribadi

Berdasarkan data diatas sejumlah responden diberikan beberapa pertanyaan terkait kondisi, serta pemahaman tentang materi yang disampaikan pada saat Bimtek tahap 1 dan tahap 2. Masa pandemi Covid-19 tentunya terdapat regulasi yang mengatur tentang bagaimana tata cara pengawasan di Pilkada 2020 termasuk kondisi Kesehatan dari PTPS yang terpilih termasuk menanyakan tentang masa pandemic Covid19 membuat PTPS apakah takut untuk terjun kelapangan sebagai anggota PTPS. Dari total jumlah responden menjawab bahwa terdapat 56 orang $(94,9 \%)$ tidak takut untuk menjadi PTPS di masa Pandemi Covid 19, 2 orang menjawab mungkin $(3,4 \%)$ dan 1 orang menjawab $\mathrm{Ya}(1,7 \%)$. Pemahaman tentang menjaga kesehatan di masa pandemi di Pilkada 2020 sangat jelas dan para PTPS merasa tidak khawatir jika harus bertugas untuk menjadi anggota pengawas di wilayahnya masing-masing. Untuk dapat lebih jelasnya dapat dilihat pada Gambar 5 dibawah ini:
Gambar 5:

Kesiapan anggota PTPS dimasa Pandemi Covid-

19

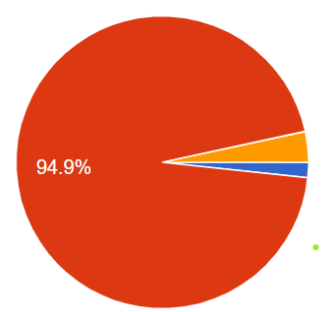

Ya

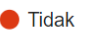

Mungkin

Sumber: Dokumentasi pribadi

Sebagai tanggung jawab untuk menjalankan tugas PTPS serta selalu menjaga protokol kesehatan tentunya Rapid Tes menjadi salah satu kewajiban bagi PPTS sebelum terjun kelapangan. Rapid Test merupakan hal yang wajib yang harus dilalui. Sebelumnya banyak yang takut untuk melakukan Rapid Test karena berbagai informasi di media sosial yang sebelumnya menganggap penderita Covid 19 dijauhi bahkan di awal kemunculan banyak stigma negative terkait pasien yang terkena Covid19. Pemahaman ini perlu disampaikan kepada Pengawas TPS untuk bersedia dilakukan Rapid Tes untuk mengetahui kondisi tubuh. Dari hasil kuesioner 100\% menjawab bahwa rapid tes penting untuk jajaran pengawas. Untuk lebih jelasnya lagi dapat dilihat pada Gambar 6 dibawah ini:

Gambar 6:

Rapid Tes penting untuk jajaran pengawas

Apakah Rapid Tes penting untuk jajaran pengawas?

59 responses

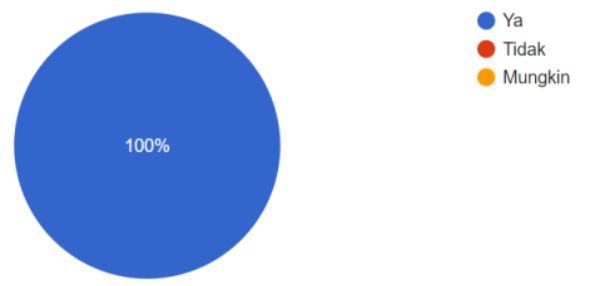

Sumber: Dokumentasi pribadi 
Pemahaman tentang pentingnya rapid tes bagi PTPS sebelum terjun kelapangan tentunya masih ada kekhawatiran bagi para anggota PTPS saat menjalankan tugas pada saat pandemi. Dari hasil kuesioner terdapat $71,2 \%$ tidak merasa khawatir untuk menjalankan tugas di masa pandemi Covid19, 20,5\% menjawab mungkin khawatir saat melakukan tugas pengawasan, dan 8,5\% menjawab Ya atau merasa khawatir dalam menjalankan tugas pengawasan. Untuk lebih jelasnya lagi dapat dilihat pada Gambar 7 dibawah ini:

\section{Gambar 7:}

Kekhawatiran PTPS saat menjalankan tugas pengawasan

Apakah anda merasa khawatir saat bertugas terutama saat masa pande 59 responses

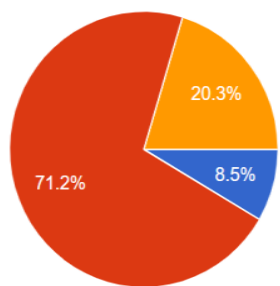

Sumber: Dokumentasi pribadi

Dari hasil kuesioner diatas tentunya dapat dilihat bahwa masih ada rasa khawatir anggota PTS dalam menjalankan tugasnya. Kekhawatiran ini tentunya akan menimbulkan rasa takut saat pelaksanaan Pilkada 2020 seperti hasil kuesioner terdapat 54 orang $(94,9 \%)$ merasa tidak takut untuk menjadi PTPS, 1 orang $(1,7 \%)$ merasa takut untuk menjadi PTPS di masa pandemi, dan 2 orang $(3,4 \%)$ menjawab mungkin ada rasa takut untuk menjadi PTPS di masa pandemi. Untuk lebih jelasnya lagi dapat lihat pada Gambar 8 dibawah ini:
Gambar 8:

Ketakutan PTPS untuk menjalankan tugas dimasa pandemi

59 responses

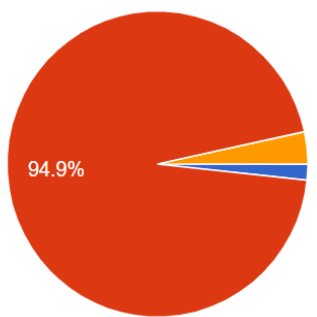

Sumber: Dokumentasi pribadi

Setelah pemahaman materi tentang protokol kesehatan bagi anggota PTPS serta berbagai materi lainnya tentunya pemahaman tentang penggunaan aplikasi siwaslu sebelum diterjunkan kelapangan saat pemungutan suara. Terdapat 56 orang atau sekitar 94,9\% menyatakan tidak ada kesulitan dalam penggunaan SIWASLU dan menguasai materi yang sudah disampaikan, 1 orang $(1,7 \%)$ merasa penggunaan laporan SIWASLU menyulitkan, dan 2 orang (3,4\%) menjawab mungkin penggunaan aplikasi SIWASLU menyulitkan. Untuk dapat lebih jelasnya lagi dapat dilihat pada Gambar 9 dibawah ini:

Gambar 9:

Pemahaman Materi Sistem Pengawas Pemilu (SIWASLU)

Apakah pengiriman laporan menggunakan Siwaslu, Form A dan Google Forms menyulitkan saudara?

59 responses
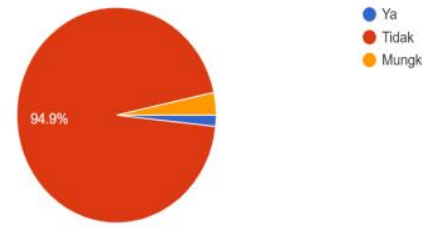

Sumber: Dokumentasi pribadi 
Berdasarkan dari pemahaman materi yang telah disampaikan oleh narasumber serta praktek dilapangan tentang komitmen PTPS untuk dapat berkontribusi kembali menjadi anggota pengawas pemilu TPS untuk pemilu 2024 responden menjawab 28 orang $(47,5 \%)$ bersedia kembali untuk menjadi PTPS pada pemilu atau pilkada yang akan datang, 28 orang $(47,5 \%)$ menjawab masih ragu atau mungkin bersedia kembali untuk menjadi PTPS dan 3 orang atau sekitar (5,1\%) tidak ingin bergabung menjadi anggota PTPS untuk Pilkada atau Pilpres tahun 2024. Untuk dapat lebih jelasnya lagi dapat dilihat pada Gambar 10 dibawah ini:

\section{Gambar 10:}

Ketersediaan kembali menjadi anggota PTPS pada Pilpres atau Pilkada 2024

Apakah anda akan ikut bergabung untuk menjadi anggota PTPS atau jajaran penga ditingkat atas saat Pilpres 2024?

59 responses
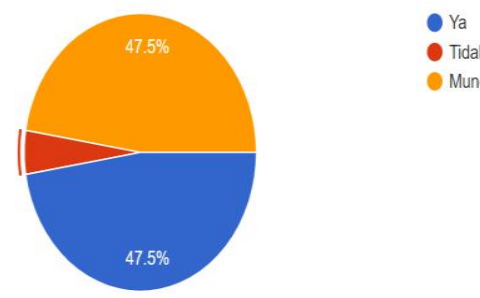
Mungkin

Sumber: Dokumentasi pribadi

\section{KESIMPULAN}

Anggota PTPS yang mengikuti bimbingan teknis tahap 1 dan 2 menyadari bahwa penugasan untuk menjadi Pengawas Tempat Pemungutan Suara di masa pandemic Covid-19 sangat berbeda dengan Pemilu atau Pilkada sebelumnya. Berbagai materi yang disampaikan seperti regulasi pemilihan pilkada tahun 2020 sesuai dengan protokol kesehatan, integritas sebagai PTPS, kode etik sebagai PTPS serta bimtek tentang penggunaan SIWASLU (Sistem Pengawasan Pemilu) dapat dipahami dengan jelas. Masih ada kehawatiran bagi anggota PTPS dalam menjalankan tugas disaat pandemi memang sangat wajar apalagi pemahaman tentang Covid-19 oleh anggota PTPS berbeda-beda tentunya penyampaian materi saat bimbingan teknis perlu dijelaskan dan dapat dipahami secara

keseluruhan sebelum para anggota PTPS diterjunkan pada hari pelaksanaan Pilkada 2020 .

\section{DAFTAR PUSTAKA}

Aida, N. R. (2020). Berikut Daftar 270 Daerah yang Gelar Pilkada Serentak 9 Desember $2020 . \quad$ Kompas.Com. https://www.kompas.com/tren/read /2020/12/05/193100165/berikutdaftar-270-daerah-yang-gelar-pilkadaserentak-9-desember-2020?page $=$ all

Chusna, F. (2020). Setelab 3 Bulan Tertunda, Tabapan Pilkada Dilanjutkan Mulai Hari Ini. Kompas.Com. https://nasional.kompas.com/read/2 020/06/15/12032331/setelah-3bulan-tertunda-tahapan-pilkadadilanjutkan-mulai-hari-ini?page $=$ all

Muharam, R. S., Sulasono, \& Sugito. (2021). Laporan Akbir Kinerja Pengawasan Pemilihan Bupati dan Wakil Bupati Kabupaten Bantul 2020.

Pengganti Undang-Undang, P. P. (2020). Perppu No 2 Tahun 2020 Tentang Perubahan Ketiga Atas Undang-Undang Nomor 1 Tabun 2015 Tentang Penetapan Peraturan Pemerintah Pengganti UndangUndang Nomor 1 Tabun 2014 Tentang Pemilihan Gubernur, Bupati, dan Walikota Menjadi Undang-Undang. Rep.

Rizki, S. C., \& Hilman, Y. A. (2020). Menakar Perbedaan Opini Dalam Agenda Pelaksanaan Kontestasi Pilkada Serentak Di Tengah Covid-19. Jurnal Ilmiah Muqoddimah: Jurnal Ilmu Sosial, Politik Dan Hummanioramaniora, 4(2), 143.

https://doi.org/10.31604/jim.v4i2.20 20.143-155 
Supriyadi. (2020). Menakar Nilai Keadilan

Penyelenggaraan Pilkada 2020 Di

Tengah Pandemi Covid-19. Kanun:

Jurnal Ilmu Hukum, 22(3), 493-514.

https://doi.org/https://doi.org/10.24

815/kanun.v22i3.17466 